\title{
Ocean acidification may alter predator-prey relationships and weaken nonlethal interactions between gastropods and crabs
}

\author{
Joshua P. Lord ${ }^{1, *}$, Elizabeth M. Harper ${ }^{2}$, James P. Barry ${ }^{3}$ \\ ${ }^{1}$ Department of Biological Sciences, Moravian College, Bethlehem, PA 18045, USA \\ ${ }^{2}$ Department of Earth Sciences, University of Cambridge, Cambridge CB2 3EQ, UK \\ ${ }^{3}$ Monterey Bay Aquarium Research Institute, Moss Landing, CA 95039, USA
}

\begin{abstract}
Predator-prey interactions often drive ecological patterns and are governed by factors including predator feeding rates, prey behavioral avoidance, and prey structural defenses. Invasive species can also play a large ecological role by disrupting food webs, driving local extinctions, and influencing evolutionary changes in prey defense mechanisms. This study documents a substantial reduction in the behavioral and morphological responses of multiple gastropod species (Nucella lapillus, N. ostrina, Urosalpinx cinerea) to an invasive predatory crab (green crab Carcinus maenas) under ocean acidification conditions. These results suggest that climate-related changes in ocean chemistry may diminish non-lethal effects of predators on prey responses including behavioral avoidance. While snails with varying shell mineralogies were similarly successful at deterring predation, those with primarily aragonitic shells were more susceptible to dissolution and erosion under high $\mathrm{CO}_{2}$ conditions. The varying susceptibility to predation among species with similar ecological roles could indicate that the impacts of invasive species like green crabs could be modulated by the ability of native and invasive prey to withstand ocean acidification conditions.
\end{abstract}

KEY WORDS: Predation $\cdot$ Nonlethal $\cdot$ Shell structure $\cdot$ Crab $\cdot$ Snail

\section{INTRODUCTION}

Climate change has the capacity to shift species interactions and interfere with established links between predators and prey in both the short term and over evolutionary time (Northfield \& Ives 2013, Lord et al. 2017). Predator-prey relationships in many systems involve the co-evolution of defense and offense in an evolutionary arms race leading to characteristics such as stronger gastropod shells and stronger crab claws (Dawkins \& Krebs 1979, Yamada \& Boulding 1998). Even if predation exerts strong selective pressure on prey, prey survival in relation to its defensive adaptations can vary considerably (Abrams 1986, Brodie \& Brodie 1999). Spe-

\footnotetext{
${ }^{*}$ Corresponding author: lordj02@moravian.edu
}

cies survival may be enhanced by phenotypic plasticity and inducible defenses, which allow individuals to produce defensive structures or chemicals only in the presence of predators (Agrawal 2001, Trussell \& Etter 2001). For example, tadpoles have wider bodies in the presence of dragonfly larvae (Kishida et al. 2009), and snails can produce thicker shells when they occupy a habitat with many predatory crabs (Appleton \& Palmer 1988), both of which increase prey survival. Outcomes of predator-prey interactions such as these can be altered by climate change if predators and prey respond differently to changing environmental conditions (Northfield \& Ives 2013, Lord et al. 2017), through mechanisms including behavioral changes and the capacity to

(C) J. Lord, E. Harper, J. Barry, Moravian College, Monterey Bay Aquarium Research Institute, Cambridge University 2019. Open Access under Creative Commons by Attribution Licence. Use, distribution and reproduction are unrestricted. Authors and original publication must be credited.

Publisher: Inter-Research · www.int-res.com 
produce defensive structures (Bibby et al. 2007, Comeau et al. 2009).

Predator avoidance plays a key role in the survival of many prey taxa, but there is increasing evidence that environmental change can affect behavior in both predators and prey. A change in prey behavior upon sensing predators is common and results in trait-mediated indirect interactions (TMII) that promote trophic cascades in food webs (Estes \& Palmsano 1974, Aschaffenburg 2008, Ellrich et al. 2016). For example, spiders, by causing herbivorous grasshoppers to reduce feeding, can positively impact herbs (Beckerman et al. 1997). If climate change interferes with the ability of prey to detect predators, it will make prey more susceptible to direct predation and may also diminish the community-wide consequences of any changes in prey behavior caused by the predators. For example, ocean acidification (OA) impairs various sensory behaviors of some larval fish (Munday et al. 2009, Dixson et al. 2010, Cattano et al. 2018), reduces survival and foraging rates for an intertidal crab (Dodd et al. 2015), and impedes the ability of some snails to detect predators (Manríquez et al. 2013, Watson et al. 2013, Jellison et al. 2016). Each of these behavioral changes could shift the balance of predator-prey interactions as well as their cascading indirect consequences within the community.

$\mathrm{OA}$ is expected to reduce the $\mathrm{pH}$ of surface ocean waters from 8.1 to 7.8 by 2100 (Pachauri et al. 2015), but parts of the west coast of North America are already experiencing intermittently lower $\mathrm{pH}$ levels due to coastal upwelling (Booth et al. 2012). OA can affect a wide range of species and can be especially harmful to calcifying organisms (Ries et al. 2009, Hofmann et al. 2010, Byrne 2011, Gazeau et al. 2013). Saturation states of coastal waters with respect to the 2 principal forms of $\mathrm{CaCO}_{3}$ (calcite and aragonite) are particularly relevant for mollusks due to the prevalence of calcified shells in this group, and shell microstructure influences the vulnerability of shelled species to dissolution or reduced shell growth with OA (Harper 2000, Parker et al. 2013). Mollusk shells function primarily as a defense against predation, and changes in shell structure due to OA could alter species' vulnerabilities to predation, limit their capacity for inducible defenses by increased calcification, and favor species that are more resilient to OA. For example, the snail Nucella lapillus produces thinner and weaker shells with elevated $\mathrm{CO}_{2}$ as both juveniles (Rühl et al. 2017) and adults (Queirós et al. 2015), which will likely make this species more vulnerable to predation. OA conditions can also reduce both behavioral responses (Jellison et al. 2016) and inducible defenses (Bibby et al. 2007) of herbivorous snails in the presence of crab predators. From the predator side, OA can inhibit crab foraging (Wu et al. 2017), reduce crushing strength (Landes \& Zimmer 2012), or lead to starvation due to reduced nutritional content of prey (e.g. barnacles; Harvey \& Moore 2017). These recent studies have emphasized the importance of understanding changes in interspecific relationships and illustrated the direct and indirect effects that OA can have on predator-prey dynamics.

In addition to changing ocean conditions related to anthropogenic climate change, the spread of invasive species can also have important ecological effects. Climate-induced changes in the vulnerability of molluscan prey may greatly influence their ability to cope with native and non-native predators and competitors. Invasive marine species like green crabs Carcinus maenas can shift community composition (Grosholz \& Ruiz 1996, McDonald et al. 2001), cause inducible defense responses in native species (Leonard et al. 1999), or even exacerbate the ecological impact of other invasive species (Grosholz 2005). Furthermore, C. maenas and other invasive predators may respond differently to environmental changes in their native range (Landes \& Zimmer 2012) than their invaded range, though physiological responses like higher feeding rates at warmer temperatures (Sanchez-Salazar et al. 1987) are likely to be relatively consistent. Because invasive predators lack an evolutionary history with native prey (and vice versa), invasive species add an additional layer of complexity in understanding of how predator-prey relationships will be affected by climate change.

The goal of the present study was to measure the impact that elevated temperature and $\mathrm{CO}_{2}$ could have on predator-prey relationships between native and invasive species. Recent studies (Ries 2011, Queirós et al. 2015, Harvey \& Moore 2017, Rühl et al. 2017) have examined snail growth and feeding under a variety of future conditions and have predicted how species will respond to predators in a changing environment. The present study builds upon this work by comparing responses of 3 snail species with varying shell composition under future ocean conditions and testing varied responses of all 3 species to a globally abundant predatory crab. The green crab C. maenas (Linnaeus, 1758) is a major predator on a variety of mollusks, including predatory snails (Grosholz \& Ruiz 1996), and was the principal predator used in the present study. Green crabs are native to western Europe but invaded the east coast of North America (by 1817), Australia (1900), South Africa (1983), Japan (1984), the west coast of the USA (1990), and 
Argentina (2003), and thus have become established on every continent except Antarctica (Carlton \& Cohen 2003, Darling et al. 2008). The present study measured the performance (feeding, survival, growth) of 3 species of predatory snails (subfamily Ocenebrinae) under current conditions, future warming, and OA, both with and without the presence of green crabs. Snail species used in these experiments had different native geographic ranges and histories of exposure to invasive green crabs. N. lapillus (Linnaeus, 1758) is native to Europe and the east coast of North America. Urosalpinx cinerea (Say, 1822) is native to the east coast of North America and invasive on the west coasts of North America and Europe (Buhle \& Ruesink 2009, Faasse \& Ligthart 2009). N. ostrina (Gould, 1852) is only found on the west coast of North America and has minimal historical exposure to green crabs, which are currently present in only a few bays along the northeast Pacific coast (Cohen et al. 1995, Turner et al. 2016). Although green crabs are not the primary predator of all 3 snail species throughout their geographic ranges, these snails were chosen as representative molluscan prey because they are abundant and display behavioral responses to predators, often in the form of reduced feeding or inducible defenses (Trussell \& Etter 2001, Lord \& Whitlatch 2012, Lord et al. 2017). Therefore, the goal was not to predict specific changes in future population sizes of these particular species, but rather to use these sets of predator-prey interactions as model systems to draw general conclusions about how warming and OA may influence predator-prey relationships. We hypothesized that OA would impair prey calcification, leading to smaller changes in shell thickness in response to predator exposure, and consequently increasing their vulnerability to predation by invasive crabs.

\section{MATERIALS AND METHODS}

\subsection{Collection of organisms}

All organisms were collected in the USA in September 2016: Nucella ostrina in Moss Landing Harbor, CA; N. lapillus in Nahant, MA; Urosalpinx cinerea in San Mateo, CA; and Carcinus maenas in Bodega Bay, CA. At the time of collection in late September, seawater temperatures in San Mateo and Nahant were approximately $16^{\circ} \mathrm{C}$, while Bodega Bay and Moss Landing were approximately $14^{\circ} \mathrm{C}$ (more detailed water measurements shown in Table S1 and Fig. S1 in the Supplement at www.int-res.com/articles/ suppl/m616p083_supp.pdf). Snails were hand-collected, and crabs were collected in traps; all were transported in a cooler by car or overnight shipping (for $N$. lapillus, $18 \mathrm{~h}$ transit time). N. lapillus were shipped in a cooler filled with ice packs and seawater-soaked paper towels to the Monterey Bay Aquarium Research Institute (MBARI) flowing seawater facility in Moss Landing, CA. Seawater in the MBARI seawater lab is supplied by a seawater intake that is $17 \mathrm{~m}$ deep and $300 \mathrm{~m}$ offshore in Monterey Bay, with temperatures typically ranging between $12^{\circ}$ and $16^{\circ} \mathrm{C}$. All organisms were kept in recirculating seawater tanks at $12^{\circ} \mathrm{C}$ and starved for $2 \mathrm{wk}$ prior to the experiment to allow organisms to recover from any transport-related stress and to standardize initial conditions. The experiment ran for $\sim 5$ mo (October 10, 2016, to March 6, 2017). Mesh filters were installed at the drain for each tank to ensure that no organisms escaped, and any egg cases were removed before they hatched (all 3 snail species are direct developers with crawl-away larvae).

\subsection{Experimental setup}

The experimental system included 8 replicates per treatment level in a fully factorial design with 3 factors of 2 levels each: $\mathrm{CO}_{2}$ (control, $\mathrm{pH}$ offset of -0.3 ), temperature (control, offset of $+2.3^{\circ} \mathrm{C}$ ), and crab (presence, absence). Control conditions were unmodified ambient seawater, with $\mathrm{CO}_{2}$ and temperature treatments maintained as an offset from these ambient, naturally fluctuating conditions (mean \pm $\mathrm{SD}, 14.47 \pm 0.85^{\circ} \mathrm{C}$ ) (as in Frieder et al. 2014, Lord et al. 2017). Incorporating natural fluctuations in $\mathrm{pCO}_{2}$ as the present experiment did by adding $\mathrm{CO}_{2}$ to ambient seawater (with diurnal cycles as well as upwelling, Table S1) is done in very few experiments, but provides valuable information about species responses to acidification under more natural conditions (Wahl et al. 2016). The different treatment combinations were randomly assigned to the 64 experimental tanks.

The $\mathrm{pH}$ was measured with Vernier ${ }^{\mathrm{TM}}$ Tris-compatible pH sensors (recorded every second), and alkalinity was assessed with an SI Analytics Titroline 7000 (at the start and end of the experiment), then $\mathrm{pCO}_{2}$, total $\mathrm{CO}_{2}$, and calcite and aragonite saturation states were calculated for each treatment using CO2SYS software (Lewis \& Wallace 1998) (Table S2 in the Supplement). The $\mathrm{pH}$ sensors were calibrated with pH 7 and 10 buffers (total pH scale) on a weekly basis for the duration of the experiment. The higher tem- 
perature treatments approximated the predicted conditions for the North Pacific in 2100 based on the Coupled Model Intercomparison Project Phase 5 (CMIP5) multi-model ensemble ranges from the 2015 Intergovernmental Panel on Climate Change (IPCC) report for representative concentration pathway 6.0 (RCP6.0) (Pachauri et al. 2015). Water was supplied from two 381 header tanks, each with 32 bulkhead fittings to supply a constant flow of $0.41 \mathrm{~min}^{-1}$ to each experimental tank. The $\mathrm{pH}$ was modified in one of the header tanks via bubbling with a $\mathrm{CO}_{2}$ /air mixture sufficient to maintain the desired 0.3 -unit $\mathrm{pH}$ reduction, also based on North Pacific estimates for 2100 under RCP6.0 (Pachauri et al. 2015). This headertank system means that $\mathrm{CO}_{2}$ treatments were not true replicates, but similar systems have been used previously for OA research (Taylor et al. 2014, Lord et al. 2017), and it was the only feasible way to implement a continuous offset, constantly changing $\mathrm{pH}$ system for all 32 elevated $\mathrm{CO}_{2}$ tanks simultaneously. Flow of the air-gas mixture was controlled by a solenoid valve attached to a MBARI-built control system which utilized LabVIEW ${ }^{\mathrm{TM}}$ (National Instruments) software and a proportional-integrative-derivative controller to keep pH 0.3 units below ambient seawater conditions.

All snails were held in individual cages within each experimental tank ( 7 l rectangular polypropylene) to assess feeding and growth while preventing predation (3 snails in each tank, 1 of each species), while crabs were uncaged in the tanks (mean sizes in Table S3 in the Supplement). All organisms were fed mussels Mytilus galloprovincialis ad libitum for the duration of the experiment; this mussel species was used because it is present in the range of all study species (and is eaten by all of them), and occurs primarily in estuaries in the northeast Pacific, like C. maenas (Braby \& Somero 2006). Crabs were provided 10 large (4 cm shell length [SL]) mussels per week and snails were provided five $1 \mathrm{~cm}$ mussels every $2 \mathrm{wk}$; feeding was quantified whenever new mussels were added. It was evident that the food supply was sufficient because crabs and snails never ate all of the supplied mussels by the time new ones were added. While all of the crab and snail species included in this study can be found in intertidal habitats in the natural environment, they were kept immersed in seawater throughout these experiments to ensure that they experienced similar exposure to the treatment conditions. Therefore, the role of increased air temperature with climate change was not assessed and potential shifts in organism responses under tidal conditions were not incorporated into this study.
While this may have made the experimental conditions less realistic, the full immersion design is characteristic of the vast majority of OA experiments and ensured that all organisms had the same exposure to future ocean conditions.

\subsection{Growth measurements}

Prior to the experiment, the following measurements were made: crab carapace width $(\mathrm{CW})$, snail shell length, snail wet weight, and snail immersed weight. The immersed weight method was used to estimate wet shell weight and wet tissue weight, using a regression between immersed shell weight and shell weight of empty shells for each species, to quantify the shell weight of live organisms (Palmer 1990, Lord \& Whitlatch 2012). The growing edge of each snail shell was painted with nail polish to mark its initial growth margin. All of the described crab and snail measurements were repeated at the end of the experiment to assess various elements of growth during the course of the experiment. Each $N$. lapillus shell was also examined for the presence or absence of aperture teeth along the growing shell margin at the end of the experiment. However, no statistical analysis was performed on this, because this trait was only examined after we observed an apparent difference between treatments; thus, it was not assessed at the start of the experiment.

Shell growth was assessed in several ways to provide a more complete picture of snail responses to changes in temperature, $\mathrm{CO}_{2}$ levels, and predator presence. Lateral shell growth was assessed as the distance between the growing shell edge and the painted initial edge, so this only provided information about lateral extension of the shell (not any internal growth). Shell density for the area of lateral extension (new shell growth) was determined by using a Dremel ${ }^{\mathrm{TM}}$ rotary tool with diamond-coated blade to cut off the region of new shell growth, measuring air weight and immersed weight of this shell region, and then using Archimedes' principle to calculate the volume and then the density of this shell section. Because no significant differences in shell density were found between treatments ( $p>0.5$ ), density differences were not considered for calculations of other shell growth parameters.

The immersed weight method described in the previous paragraph was used to estimate the entire shell weight (not just the growing edge where lateral growth occurred) of each snail both at the start and the end of the experiment, enabling calculation of 
shell weight gain during the experiment. The ratio between shell weight gain and lateral shell growth was calculated to understand how snails allocated new shell material between shell thickening (adding shell material to the internal surface of the existing shell) and lateral shell growth (extending their shell laterally). Higher shell weight gain:lateral shell growth ratios would indicate more allocation towards shell thickening, and lower values would suggest a relative favoring of shell extension over shell thickening.

The microstructure of shells for all snail species was examined using a scanning electron microscope (SEM). Shells were dried, embedded in resin, and cross-sectioned latitudinally through the whorls. Cross-sections were polished and then etched in 1\% $\mathrm{HCl}$ and mounted on SEM stubs (FEI QEMSCAN 650F) where the internal shell microstructure could be observed. The last whorl of an individual of each species was ground and homogenized, then analyzed with Rietveld quantitative analysis (Bish \& Howard 1988) to obtain accurate measures of calcite and aragonite ratios. Because shell composition can vary depending on the part of the shell examined (Harper 2000, Queirós et al. 2015, Rühl et al. 2017), the Rietveld analysis was only performed on the last whorl for all of the snail species (the newest part of the shell), and all snail individuals were of similar sizes to minimize any variability in age. The latitudinal cross-sections of the snail shells were also done on similarly sized individuals and were only used to observe relative thickness of calcite and aragonite layers; these were not used for any quantitative analysis. To compare general patterns in shell structure, 3D models of the shell of each species were created with a Siemens Inveon multimodality computed tomography (CT) scanner at the UC Davis Center for Molecular and Genomic Imaging. Because this was not used for quantitative analysis, just to visualize changes in shell structure, only 2 individuals of each species from each treatment were used.

\subsection{Green crab prey preference experiment}

An additional 2 wk feeding experiment was conducted under control seawater conditions (ambient flowing seawater) to assess relative feeding rates of C. maenas on each of the 3 snail species. One crab and 3 snails of each species (all $\sim 2 \mathrm{~cm} \mathrm{SL}$ ) were held in each of 7 aerated seawater tanks $(20 \mathrm{~cm} \times 20 \mathrm{~cm} \times$ $40 \mathrm{~cm}$ ). After the experiment, the number of snails that were eaten or damaged was counted. Feeding rates determined from this experiment were combined with estimates of shell production from the previous experiment (Section 2.3) to estimate snail survival rates as a function of $\mathrm{pCO}_{2}$, as described below (Section 2.5).

\subsection{Statistical analyses}

For all statistical tests on the factorial climate change experiment, the sample sizes were 8 for each of the treatments ( 1 snail in each of 8 replicate tanks per treatment), and differences in growth between treatment levels were calculated using a 3-way ANOVA in SigmaStat ${ }^{\mathrm{TM}}$ software. Fisher LSD post hoc tests were used to compare between individual treatments. Multiple linear regressions (MLR) were performed for each of the growth parameters, using dummy variables for each level of each treatment in order to determine the proportion of the variance explained by each of the factors (temperature, $\mathrm{CO}_{2}$, $\mathrm{crab}$ ). Prior to all of the ANOVA and MLR tests, data were tested for normality (Shapiro-Wilk test) and equality of variance (Brown-Forsythe) in SigmaStat. Most met these assumptions (non-significant), but any dependent variables that failed the normality test were log-transformed in Excel and then passed the test in SigmaStat.

To compare lateral growth rates across all 3 species in the same graph, growth rates were divided by the average growth rates for each species under control conditions, accounting for inter-specific differences in growth. This was only done for visual comparison, and not for statistical analysis, though patterns within each species were unaffected by this transformation. Added shell thickness was inferred from added shell weight divided by lateral growth.

The adjusted saturation state under each set of environmental conditions was calculated separately for each species based on the respective calcite: aragonite ratios of their shells determined by Rietveld analysis (Bish \& Howard 1988). For example, a species with a $50 \%$ aragonite and $50 \%$ calcite shell would have an adjusted saturation state halfway in between the aragonite and calcite saturation states. The added shell thickness to adjusted saturation state plot was fit with a 2-parameter modified power function $\left(y=a\left(1-x^{-b}\right)\right)$ in SigmaStat to highlight the general relationship between added shell thickness and saturation state. Added shell weight was also plotted as a function of adjusted saturation state, with the same power function. To visualize how snail survival may change over time as a function of green 
crab predation and $\mathrm{pCO}_{2}$, the power function was flipped horizontally to fit the thickness- $\mathrm{pCO}_{2}$ relationship and scaled vertically with observed predation rates by $C$. maenas on each species.

\section{RESULTS}

There were no significant differences in green crab (Carcinus maenas) feeding, growth, or survival under the different temperature and $\mathrm{CO}_{2}$ conditions $(\mathrm{p}>$ 0.2 ), though there was a significant interaction between temperature and $\mathrm{CO}_{2}$ level for crab feeding (Table S4 in the Supplement). All crabs survived for the duration of the experiment, with overall mean consumption of $50.4 \mathrm{~g}$ mussel tissue per week (SD = $3.9 \mathrm{~g})$ and average growth of $10.5 \mathrm{~mm} \mathrm{CW}$ ( $\mathrm{SE}=$ $1.4 \mathrm{~mm})$.

Shell growth (in terms of shell weight added) by the 3 snail species varied in relation to $\mathrm{CO}_{2}$ conditions; Urosalpinx cinerea exposed to high $\mathrm{CO}_{2}$ treatments lost shell mass during the experiment (3-way ANOVA, $\left.F_{1,55}=14.3, \mathrm{p}<0.001\right)$ while the Nucella species showed no significant response. In all treatments, $N$. ostrina grew enormously, in some cases doubling in shell weight over the course of the $\sim 5 \mathrm{mo}$ experiment. MLR revealed that crab presence accounted for over $90 \%$ of the variability in shell weight changes for N. ostrina, compared to approximately $80 \%$ for $N$. lapillus and $<10 \%$ for $U$. cinerea, for which $\mathrm{CO}_{2}$ was the dominant factor (Fig. 1). The power of the $F$-tests for the statistical comparisons made in this study ranged between 0.45 and 0.90 , so there was a chance of underestimating differences between treatments (type II error).

The interaction between crab effects and $\mathrm{CO}_{2}$ was notable for all 3 snail species, with substantially lower impacts of crab presence on lateral growth and other growth measures under high $\mathrm{CO}_{2}$ conditions (Fig. 2, Table S4). Both N. ostrina and U. cinerea showed significant interaction terms between crab presence and several measures of growth (Table S4), though elevated $\mathrm{CO}_{2}$ conditions did not significantly change the impact of crab presence on feeding rates of these species.

The presence of aperture teeth on $N$. lapillus did not vary consistently with any factor, but there was a notable difference between the presence of aperture teeth with $(86.7 \%, \mathrm{n}=15)$ and without crabs $(40.0 \%$, $\mathrm{n}=15$ ) only under elevated $\mathrm{CO}_{2}$ conditions. The opposite pattern appeared under control conditions, as a lower proportion of the snails produced teeth with $(53.9 \%)$ than without $(75 \%)$ the presence of

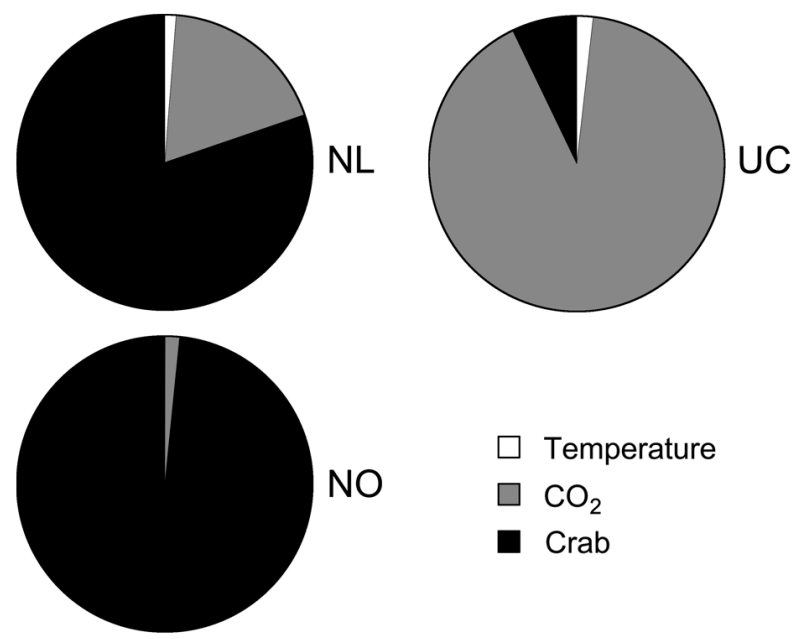

Fig. 1. Proportion of variance in snail shell growth data explained by increased temperature, high $\mathrm{CO}_{2}$, and crab (Carcinus maenas) treatments for Nucella lapillus (NL), $N$. ostrina (NO), and Urosalpinx cinerea (UC)

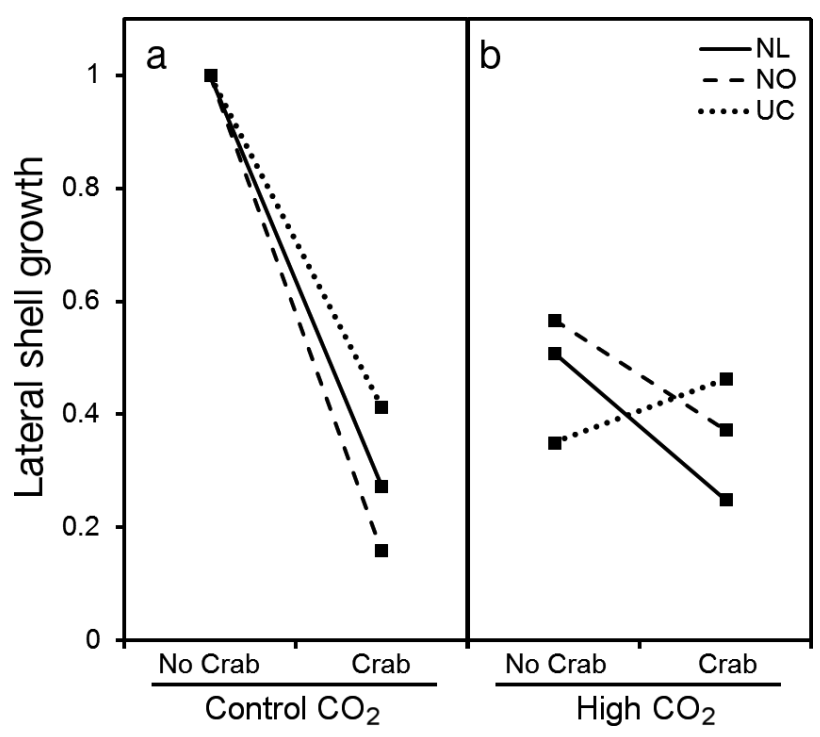

Fig. 2. Lateral shell growth for Nucella lapillus (NL), N. ostrina (NO), and Urosalpinx cinerea (UC) with and without the presence of crabs Carcinus maenas under (a) control and (b) elevated $\mathrm{CO}_{2}$ conditions. Because of disparate growth rates across species, growth rates were scaled to 1 by dividing all values by the growth rate under control conditions (thus all growth rates are 1 at control $\mathrm{CO}_{2}$ levels in the absence of crabs). This precluded the use of error bars, but this figure demonstrates overall patterns; there was a consistent decrease in growth in the presence of crabs only under control $\mathrm{CO}_{2}$ levels

crabs. Statistical comparisons were not made for this characteristic because it was only noted after the conclusion of the experiment, so there was no way to determine how many snails had aperture teeth prior to the experiment. 
There was a strong asymptotic relationship between saturation state and the ratio of shell weight gain : lateral growth $(\mathrm{p}<0.001, \mathrm{r}=0.83)$ as well as just shell weight gain $(\mathrm{p}<0.001, \mathrm{r}=0.86)$, with a steep decline below a saturation state of $\sim 1.5$ (Fig. 3). For similarly sized (approx. $2 \mathrm{~cm} \mathrm{SL}$ ) individuals, $N$. lapillus had the thickest shells $(2.3 \mathrm{~mm})$ compared to $N$. ostrina $(1.4 \mathrm{~mm})$ and $U$. cinerea $(1.1 \mathrm{~mm})$ prior to the experiment.

In the 2 wk crab predation experiment, mortality rates were $6.7 \%(2 / 30)$ for $N$. lapillus, $9.5 \%(2 / 21)$ for $U$. cinerea, and $61.9 \%(13 / 21)$ for $N$. ostrina (Freeman-Halton extension of Fisher exact probability test, $\mathrm{p}<0.001)$. Because thinner shells lead to weaker defenses against predators, the schematic diagram in Fig. 4 shows a projected decrease in survival for $U$. cinerea at lower $\mathrm{pCO}_{2}$ levels than the Nucella species, due to its more soluble primarily aragonite shell (Ries et al. 2009).
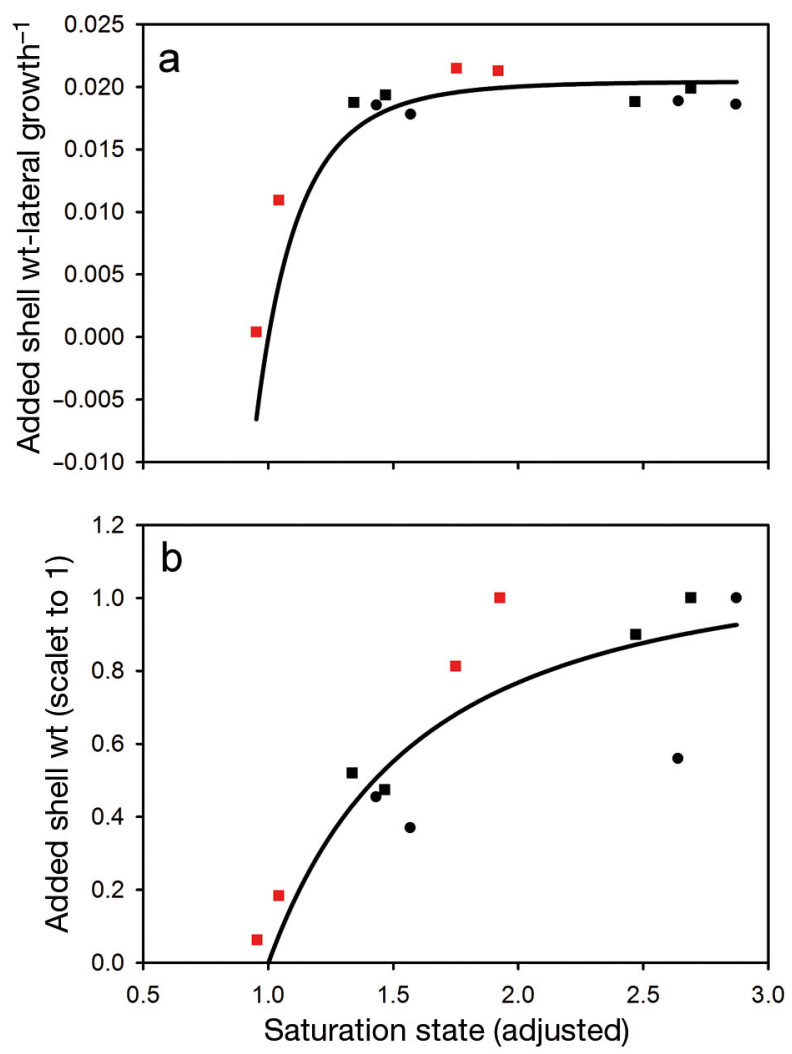

Fig. 3. (a) Ratio of shell weight gain: lateral growth and (b) shell weight increase over the duration of the experiment as a function of respective saturation states for each snail species. Data for Urosalpinx cinerea ( $\bullet$ ) are primarily based on aragonite saturation states because the shell of this species is mostly composed of aragonite. Nucella ostrina (घ) and $N$. lapillus $(\bullet)$ are primarily composed of calcite. Saturation states for each species were calculated based on seawater chemistry and on the relative calcite:aragonite ratio of each species

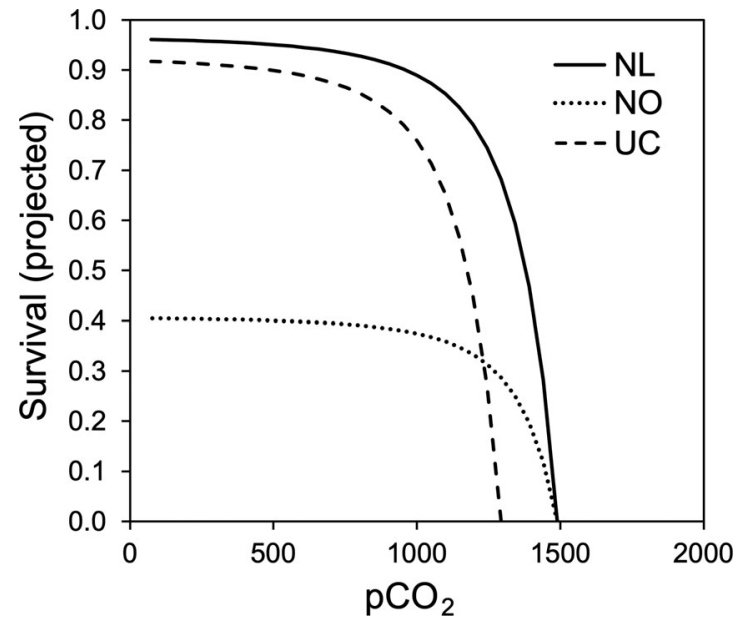

Fig. 4. Projected survival rates of Nucella lapillus (NL), N. ostrina (NO), and Urosalpinx cinerea (UC) as a function of $\mathrm{pCO}_{2}$, using a combination of shell production curves from Fig. 3a and experimental predation rates of Carcinus maenas on each snail species

For the shell microstructure analysis, Rietveld quantitative analyses of non-experimental individuals of each species showed the calcite and aragonite composition of each species: N. lapillus, $92.7 \%$ calcite, $7.3 \%$ aragonite $( \pm 1.3 \%) ; N$. ostrina, $75.2 \%$ calcite, $24.8 \%$ aragonite $( \pm 3.9 \%)$; and $U$. cinerea, $2.2 \%$ calcite, $97.8 \%$ aragonite $( \pm 1.3 \%)$. Calcite was primarily homogeneous, while aragonite in all 3 species displayed a crossed-lamellar structure (Fig. 5).

There was visible dissolution in SEM images of the exterior shell of $U$. cinerea under elevated $\mathrm{CO}_{2}$ conditions, with a reduction in thin bands of calcite and erosion of aragonite layers, exposing crossedlamellar aragonite microstructure (Fig. 5). The dissolution of $U$. cinerea shells was also visible in the MicroCT images, which show smoothing of the exterior of the shell and substantial thinning throughout the shell structure (Fig. 6).

\section{DISCUSSION}

The 3 snail species in this study varied widely in their growth responses to OA, possibly driven by differences in their shell composition. While temperature had little impact on shell growth in any species, the aragonite shell of Urosalpinx cinerea was heavily eroded under OA conditions and elevated $\mathrm{CO}_{2}$ had a larger influence on variability in shell growth than did the presence of crabs. This pattern was not consistent with the 2 Nucella species, whose growth was primarily influenced by the presence or absence of 

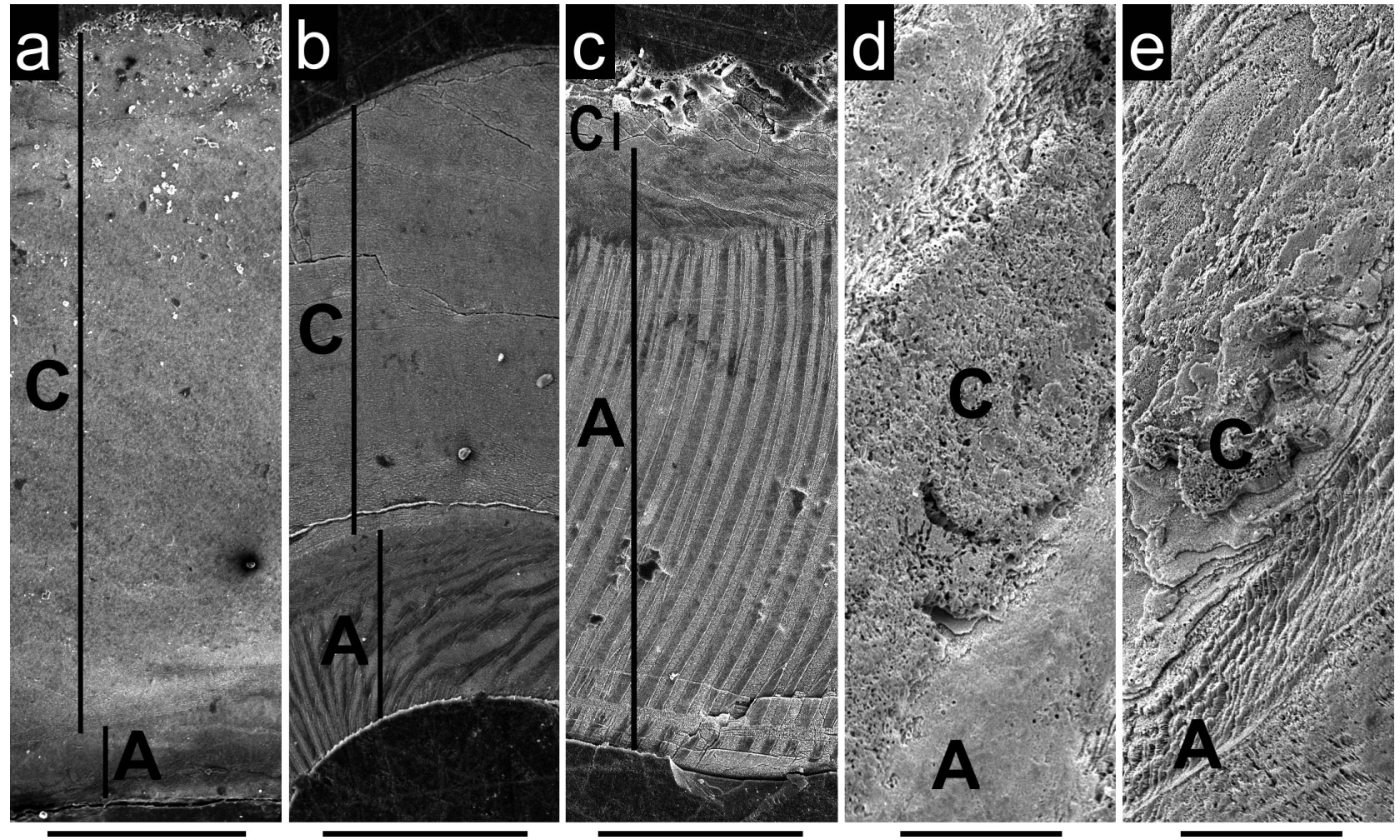

Fig. 5. Scanning electron microscopy. Shell cross-sections of (a) Nucella lapillus, (b) N. ostrina, and (c) Urosalpinx cinerea. Vertical black bars and letters indicate shell layers and mineralogy: $\mathrm{C}=$ homogeneous calcite, $\mathrm{A}=$ crossed-lamellar aragonite, with the Nucella species primarily composed of calcite and $U$. cinerea primarily aragonite. Exterior of the shell of $U$. cinerea under (d) control and (e) high $\mathrm{CO}_{2}$ conditions. Horizontal scale bars equal (a,d,e) $500 \mu \mathrm{m}$ and (b,c) $250 \mu \mathrm{m}$

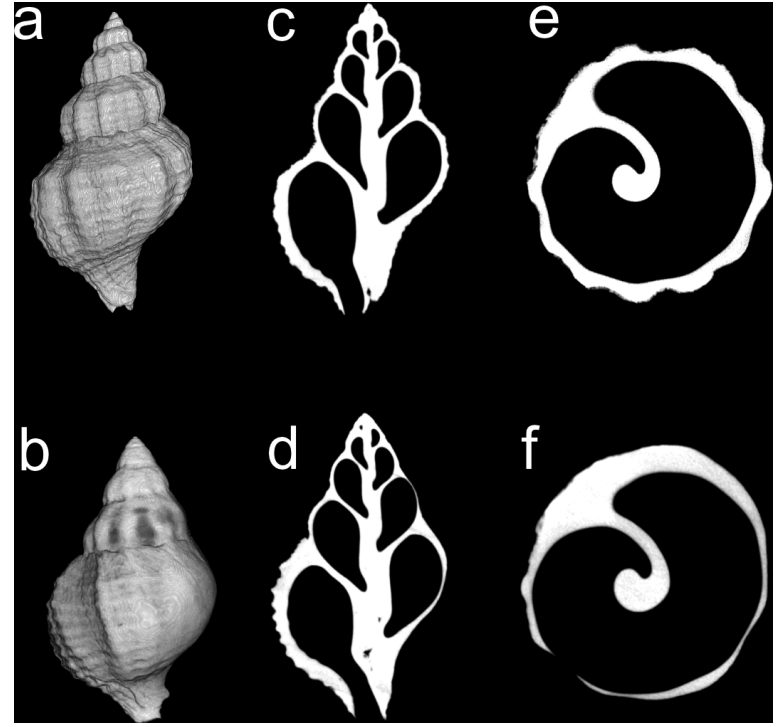

Fig. 6. MicroCT images of Urosalpinx cinerea shells from several angles under $(\mathrm{a}, \mathrm{c}, \mathrm{e})$ control and $(\mathrm{b}, \mathrm{d}, \mathrm{f})$ acidified conditions. $(a, b)$ The 3D reconstructions show smoothing of the exterior of the shell under (b) high $\mathrm{CO}_{2}$ conditions. Longitudinal sections highlight thicker shells in (c) control than (d) high $\mathrm{CO}_{2}$ treatments. Cross-sections show smoothing and thinning of shells under (f) high $\mathrm{CO}_{2}$ conditions relative to (e) controls predatory green crabs. This differential response to OA across species with similar ecological niches suggests that the future susceptibility of species to invasive predators like green crabs could be dependent on changing ocean chemistry that could hinder defense mechanisms like shell production. Species with shells that are more vulnerable to OA will become increasingly threatened by predation by crushing predators, particularly if the predators are resilient to OA.

As in previous studies on mollusk calcification (e.g. Waldbusser et al. 2015), saturation state appeared to play a large role in governing shell production, with steep declines in shell growth below aragonite or calcite saturation states of 1.5. While an array of factors including shell microstructure, magnesium content, and periostracum thickness likely play a role in the response of shelled species to OA, the calcite:aragonite ratio was highly predictive of species' responses in this study. For these and other species lacking a thick periostracum, shell mineralogy appears to have strong predictive value of species' vulnerabilities to OA (Ries 2011). This has been established for $N$. lapillus adults (Queirós et al. 2015) and juveniles 
(Rühl et al. 2017) in the past, but the inclusion of $U$. cinerea and $N$. ostrina in the same experiment enables a direct comparison between responses of species with differing shell characteristics.

Acidification may also favor the development of shell structures like aperture teeth, which can increase the defensive capacity of the shell with less calcification than would be required to produce a thicker shell. This notion is supported by the finding that while aperture teeth were common under control conditions, $N$. lapillus appeared to produce aperture teeth in response to crabs only under high $\mathrm{CO}_{2}$ conditions. Because we did not examine shells for aperture teeth prior to this experiment, we cannot conclusively determine whether they were caused by the presence of the crabs, but it is an area worthy of future research. While such additional shell structures under OA may be counterintuitive, aperture teeth reduce the size of the aperture and limit the ability of crabs to pull snails from their shells, much as shell thickening, but with less calcium carbonate. As such, it may be a more efficient defense under reduced carbonate saturation conditions, suggesting that OA could favor an adaptive shift toward defensive shell structures. In addition, snail species may be able to undergo some type of compensatory development (Rühl et al. 2017) to counteract the negative effects of OA on shell formation, but this would likely require a shift in energy allocation or life history strategies that could negatively impact growth rates, reproduction, or survival. It is also possible that changing environmental conditions (e.g. lower dissolved oxygen or elevated temperatures) could either mitigate or compound the negative impacts of OA on both shell formation and behavioral responses of mollusk and other shelled marine species (Kroeker et al. 2014).

Shell structures that deter predation vary widely among gastropods (Vermeij 1995), but it appears that 2 morphologies, (1) a thick, primarily calcite shell (like N. lapillus) and (2) a thin, primarily crossedlamellar aragonite shell (like $U$. cinerea), represent alternative evolutionary solutions to defend against crushing predators. In the present study, the species with thick calcite shells ( $N$. lapillus) was far more resilient to $\mathrm{OA}$, indicating that this morphology is likely to be increasingly adaptive under projected future ocean conditions. Thus, the strong negative response of the primarily aragonitic $U$. cinerea to elevated $\mathrm{CO}_{2}$ conditions suggests that the predator defense mechanism of developing a mechanically stronger aragonite shell may be an evolutionary deadend under increasing OA (Gabriel 1981, Harper 2000,
Trussell \& Etter 2001). While we are unable to draw generalized conclusions about the evolutionary strategies of snails with respect to shell mineralogy, the differences in shell composition between the species in this study would clearly lead to differential survival in the presence of a crushing predator like Carcinus maenas. As such, the predator-prey arms race (Dawkins \& Krebs 1979, Yamada \& Boulding 1998) between crabs and snails may shift with climate change as selection intensifies for species resilient to new environmental norms, as well as their predators.

Notably, the snail with least historical exposure to green crabs ( $N$. ostrina) showed the strongest growth and behavioral response to crab presence, suggesting that this response is prompted by a generic crab cue or by sensing damaged prey. In addition, the relatively thin, $75 \%$ calcite shell of $N$. ostrina was ineffective in preventing crab predation, indicating that expansion of green crabs onto outer shores of the northeast Pacific may negatively affect populations of this and other snails with similar shell structure. This negative effect could be exacerbated by the reduced avoidance of predators by snails (like the representative examples in this study) under elevated $\mathrm{CO}_{2}$ conditions, which could lead to even higher predation rates. While this study did not examine adaptation or selection, it is likely that selection would favor individuals or lineages capable of sensing and responding to predator cues under future conditions, but it is unclear whether current snail populations have the capacity to adapt to the rapid pace and expected magnitude of OA.

It is important to note that the snail species chosen in this study were selected as representative prey because they occupy similar ecological niches and have similar diets but have varied shell composition. Of the 3 species, N. lapillus has the longest shared evolutionary history with green crabs, but we do not suggest that shell evolution in any of these species has been shaped by C. maenas in particular. Rather, C. maenas served as a representative crushing predator in this study and clearly had the capacity and willingness to consume all of the snail species; actually exposing all 3 species to predation confirmed the prediction (from microstructure analysis) that the aragonite shells and thick calcite shells were most effective at deterring predation under current ocean conditions. This study was not intended to predict specific outcomes of predator-prey relationships between green crabs and these snail species, but rather to draw general conclusions about the future direction of relationships between crushing preda- 
tors and snails with varying shell composition. Additionally, the 'future' ocean conditions included in this study were at $\mathrm{pH}$ and temperature levels not expected to occur globally for the next $80 \mathrm{yr}$, so species' responses over that longer time frame may include evolutionary changes in susceptibility to OA. By comparing 3 similar species, this study was able to compare the relative responses of species with different shell types, enabling the prediction that species with thin aragonite shells will struggle to defend themselves from crushing predators under OA conditions. However, it is important to point out that shallow bays, estuaries, and upwelling regions already experience many of these 'future' conditions on a daily or seasonal basis, so the findings in this study are applicable to these regions even now. Future studies could examine predator-prey relationships in these locations to test some of the predictions in this study.

Climate change may cause unexpected and unpredictable shifts in the behavioral responses of prey to predators, as elevated $\mathrm{CO}_{2}$ can reduce the ability of prey to sense or respond to predators (Bibby et al. 2007, Munday et al. 2009, Dixson et al. 2010, Manríquez et al. 2013, Watson et al. 2013, Clements \& Hunt 2015, Jellison et al. 2016, Ashur et al. 2017). The weaker nonlethal effect of crabs on all 3 snail species under elevated $\mathrm{CO}_{2}$ conditions suggests that OA may impair snail sensory abilities or that the gastropods ignore predator cues under low $\mathrm{pH}$, high $\mathrm{CO}_{2}$ conditions. Limited ability to avoid predators should elevate the risk of predation, thereby intensifying direct predation effects and diminishing prey populations. Beyond the population-level consequences, a combination of reduced avoidance behavior and limited shell thickening in response to predators under future OA conditions could significantly alter food webs that are governed by indirect interactions. Indirect predator effects driven by prey behavioral responses can be more important than direct predation in many systems (Trussell et al. 2003, Werner \& Peacor 2003, Grabowski \& Kimbro 2005); weakening these links could cause cascading impacts across trophic levels. Climate change is likely to have an escalating influence on the balance of predator-prey arms races, leading to strong direct effects on the outcomes of species interactions and pervasive indirect consequences for the structure and function of entire marine ecosystems.

Acknowledgements. The $\mathrm{CO}_{2}$ control system could not have been built without the assistance of Dale Graves, Chad Kecy, and Chris Lovera. This study utilized used data col- lected by the Partnership for Interdisciplinary Studies of Coastal Oceans (PISCO), a long-term ecological consortium funded primarily by the Gordon and Betty Moore Foundation and David and Lucile Packard Foundation. Field collections of mussels, crabs, and whelks were made under California Department of Fish and Wildlife Scientific Collecting Permit SCP-12647. This research was supported by the David and Lucile Packard Foundation and NSF Award no. OCE-1416877 (to J.P.B.).

\section{LITERATURE CITED}

Abrams PA (1986) Adaptive responses of predators to prey and prey to predators: the failure of the arms-race analogy. Evolution 40:1229-1247

Agrawal AA (2001) Phenotypic plasticity in the interactions and evolution of species. Science 294:321-326

Appleton RD, Palmer AR (1988) Water-borne stimuli released by predatory crabs and damaged prey induce more predator-resistant shells in a marine gastropod. Proc Natl Acad Sci USA 85:4387-4391

Aschaffenburg MD (2008) Different crab species influence feeding of the snail Nucella lapillus through traitmediated indirect interactions. Mar Ecol 29:348-353

Ashur MM, Johnston NK, Dixson DL (2017) Impacts of ocean acidification on sensory function in marine organisms. Integr Comp Biol 57:63-80

Beckerman AP, Uriarte M, Schmitz OJ (1997) Experimental evidence for a behavior-mediated trophic cascade in a terrestrial food chain. Proc Natl Acad Sci USA 94: 10735-10738

Bibby R, Cleall-Harding P, Rundle S, Widdicombe S, Spicer $\mathrm{J}$ (2007) Ocean acidification disrupts induced defences in the intertidal gastropod Littorina littorea. Biol Lett 3: 699-701

Bish DL, Howard SA (1988) Quantitative phase analysis using the Rietveld method. J Appl Cryst 21:86-91

* Booth JAT, McPhee-Shaw EE, Chua P, Kingsley E and others (2012) Natural intrusions of hypoxic, low pH water into nearshore marine environments on the California coast. Cont Shelf Res 45:108-115

*Baby CE, Somero GN (2006) Ecological gradients and relative abundance of native (Mytilus trossulus) and invasive (Mytilus galloprovincialis) blue mussels in the California hybrid zone. Mar Biol 148:1249-1262

Brodie EDI, Brodie EDJ (1999) Predator-prey arms races: asymmetrical selection on predators and prey may be reduced when prey are dangerous. Bioscience 49:557-568

* Buhle ER, Ruesink JL (2009) Impacts of invasive oyster drills on Olympia oyster (Ostrea lurida Carpenter 1864) recovery in Willapa Bay, Washington, United States. J Shellfish Res 28:87-96

Byrne M (2011) Impact of ocean warming and ocean acidification on marine invertebrate life history stages: vulnerabilities and potential for persistence in a changing ocean. Oceanogr Mar Biol Annu Rev 49:1-42

* Carlton JT, Cohen AN (2003) Episodic global dispersal in shallow water marine organisms: the case history of the European shore crabs Carcinus maenas and C. aestuarii. J Biogeogr 30:1809-1820

Cattano C, Claudet J, Domenici P, Milazzo M (2018) Living in a high $\mathrm{CO}_{2}$ world: a global meta-analysis shows multiple trait-mediated fish responses to ocean acidification. Ecol Monogr 88:320-335 
Clements JC, Hunt HL (2015) Marine animal behaviour in a high $\mathrm{CO}_{2}$ ocean. Mar Ecol Prog Ser 536:259-279

Cohen AN, Carlton JT, Fountain MC (1995) Introduction, dispersal and potential impacts of the green crab Carcinus maenas in San Francisco Bay, California. Mar Biol 122:225-237

Comeau S, Gorsky G, Jeffree R, Teyssié JL, Gattuso JP (2009) Impact of ocean acidification on a key Arctic pelagic mollusc (Limacina helicina). Biogeosciences 6: 1877-1882

Darling JA, Bagley MJ, Roman J, Tepolt CK, Geller JB (2008) Genetic patterns across multiple introductions of the globally invasive crab genus Carcinus. Mol Ecol 17: 4992-5007

Dawkins R, Krebs JR (1979) Arms races between and within species. Proc R Soc Lond B 205:489-511

* Dixson DL, Munday PL, Jones GP (2010) Ocean acidification disrupts the innate ability of fish to detect predator olfactory cues. Ecol Lett 13:68-75

Dodd LF, Grabowski JH, Piehler MF, Westfield I, Ries JB (2015) Ocean acidification impairs crab foraging behaviour. Proc R Soc B 282:20150333

* Ellrich JA, Scrosati RA, Bertolini C, Molis M (2016) A predator has nonconsumptive effects on different life-history stages of a prey. Mar Biol 163:5

Estes JA, Palmisano JF (1974) Sea otters: their role in structuring nearshore communities. Science 185:1058-1060

Faasse M, Ligthart M (2009) American (Urosalpinx cinerea) and Japanese oyster drill (Ocinebrellus inornatus) (Gastropoda: Muricidae) flourish near shellfish culture plots in the Netherlands. Aquat Invasions 4:321-326

Frieder CA, Gonzalez JP, Bockmon EE, Navarro MO, Levin LA (2014) Can variable $\mathrm{pH}$ and low oxygen moderate ocean acidification outcomes for mussel larvae? Glob Change Biol 20:754-764

* Gabriel J (1981) Differing resistance of various mollusc shell materials to simulated whelk attack. J Zool 194:363-369

Gazeau F, Parker LM, Comeau S, Gattuso JP and others (2013) Impacts of ocean acidification on marine shelled molluscs. Mar Biol 160:2207-2245

* Grabowski JH, Kimbro DL (2005) Predator-avoidance behavior extends trophic cascades to refuge habitats. Ecology 86:1312-1319

Grosholz ED (2005) Recent biological invasion may hasten invasional meltdown by accelerating historical introductions. Proc Natl Acad Sci USA 102:1088-1091

* Grosholz ED, Ruiz GM (1996) Predicting the impact of introduced marine species: lessons from the multiple invasions of the European green crab Carcinus maenas. Biol Conserv 78:59-66

Harper EM (2000) Are calcitic layers an effective adaptation against shell dissolution in the Bivalvia? J Zool 251: 179-186

Harvey B, Moore P (2017) Ocean warming and acidification prevent compensatory response in a predator to reduced prey quality. Mar Ecol Prog Ser 563:111-122

Kofmann GE, Barry JP, Edmunds PJ, Gates RD, Hutchins DA, Klinger T, Sewell MA (2010) The effect of ocean acidification on calcifying organisms in marine ecosystems: an organism-to-ecosystem perspective. Annu Rev Ecol Evol Syst 41:127-147

Jellison BM, Ninokawa AT, Hill TM, Sanford E, Gaylord B (2016) Ocean acidification alters the response of intertidal snails to a key sea star predator. Proc R Soc B 283: 20160890
Kishida O, Trussell GC, Nishimura K (2009) Top-down effects on antagonistic inducible defense and offense. Ecology 90:1217-1226

Kroeker KJ, Sanford E, Jellison BM, Gaylord B (2014) Predicting the effects of ocean acidification on predatorprey interactions: a conceptual framework based on coastal molluscs. Biol Bull 226:211-222

* Landes A, Zimmer M (2012) Acidification and warming affect both a calcifying predator and prey, but not their interaction. Mar Ecol Prog Ser 450:1-10

Leonard GH, Bertness MD, Yund PO (1999) Crab predation, waterborne cues, and inducible defenses in the blue mussel, Mytilus edulis. Ecology 80:1-14

Lewis E, Wallace D (1998) Program developed for $\mathrm{CO}_{2}$ system calculations. Carbon Dioxide Information Analysis Center, managed by Lockheed Martin Energy Research Corporation for the US Department of Energy, Oak Ridge, TN

*Lord JP, Whitlatch RB (2012) Inducible defenses in the eastern oyster Crassostrea virginica Gmelin in response to the presence of the predatory oyster drill Urosalpinx cinerea Say in Long Island Sound. Mar Biol 159:1177-1182

Lord JP, Barry JP, Graves DG (2017) Impact of climate change on direct and indirect species interactions. Mar Ecol Prog Ser 571:1-11

*Manríquez PH, Jara ME, Mardones ML, Navarro JM and others (2013) Ocean acidification disrupts prey responses to predator cues but not net prey shell growth in Concholepas concholepas (loco). PLOS ONE 8:e68643

*McDonald PS, Jensen GC, Armstrong DA (2001) The competitive and predatory impacts of the nonindigenous crab Carcinus maenas (L.) on early benthic phase Dungeness crab Cancer magister Dana. J Exp Mar Biol Ecol 258:39-54

Munday PL, Dixson DL, Donelson JM, Jones GP, Pratchett MS, Devitsina GV, Døving KB (2009) Ocean acidification impairs olfactory discrimination and homing ability of a marine fish. Proc Natl Acad Sci USA 106:1848-1852

Northfield TD, Ives AR (2013) Coevolution and the effects of climate change on interacting species. PLOS Biol 11: e1001685

Pachauri RK, Mayer L, Intergovernmental Panel on Climate Change (IPCC) (eds) (2015) Climate change 2014: synthesis report. IPCC, Geneva

Palmer AR (1990) Effect of crab effluent and scent of damaged conspecifics on feeding, growth, and shell morphology of the Atlantic dogwhelk Nucella lapillus (L.). In: Johannesson K, Raffaelli DG, Ellis CJH (eds) Progress in littorinid and muricid biology. Springer, Berlin, p 155-182

* Parker L, Ross P, O'Connor W, Pörtner H, Scanes E, Wright J (2013) Predicting the response of molluscs to the impact of ocean acidification. Biology (Basel) 2:651-692

*Queirós AM, Fernandes JA, Faulwetter S, Nunes J and others (2015) Scaling up experimental ocean acidification and warming research: from individuals to the ecosystem. Glob Change Biol 21:130-143

Ries JB (2011) Skeletal mineralogy in a high- $\mathrm{CO}_{2}$ world. J Exp Mar Biol Ecol 403:54-64

Ries JB, Cohen AL, McCorkle DC (2009) Marine calcifiers exhibit mixed responses to $\mathrm{CO}_{2}$-induced ocean acidification. Geology 37:1131-1134

Rühl S, Calosi P, Faulwetter S, Keklikoglou K, Widdicombe S, Queirós AM (2017) Long-term exposure to elevated $\mathrm{pCO}_{2}$ more than warming modifies early-life shell growth in a temperate gastropod. ICES J Mar Sci 74:1113-1124 
Sanchez-Salazar ME, Griffiths CL, Seed R (1987) The effect of size and temperature on the predation of cockles Cerastoderma edule (L.) by the shore crab Carcinus maenas (L.). J Exp Mar Biol Ecol 111:181-193

Taylor JR, Lovera C, Whaling PJ, Buck KR, Pane EF, Barry JP (2014) Physiological effects of environmental acidification in the deep-sea urchin Strongylocentrotus fragilis. Biogeosciences 11:1413-1423

Trussell GC, Etter RJ (2001) Integrating genetic and environmental forces that shape the evolution of geographic variation in a marine snail. In: Hendry AP, Kinnison MT (eds) Microevolution rate, pattern, process. Springer, Berlin, p 321-337

Trussell GC, Ewanchuk PJ, Bertness MD (2003) Trait-mediated effects in rocky intertidal food chains: predator risk cues alter prey feeding rates. Ecology 84:629-640

Turner BC, de Rivera CE, Grosholz ED, Ruiz GM (2016) Assessing population increase as a possible outcome to management of invasive species. Biol Invasions 18: 533-548

Vermeij G (1995) A natural history of shells. Princeton University Press, Princeton, NJ

Wahl M, Saderne V, Sawall Y (2016) How good are we at

Editorial responsibility: Romuald Lipcius,

Gloucester Point, Virginia, USA assessing the impact of ocean acidification in coastal systems? Limitations, omissions and strengths of commonly used experimental approaches with special emphasis on the neglected role of fluctuations. Mar Freshw Res 67: 25-36

Waldbusser GG, Hales B, Langdon CJ, Haley BA and others (2015) Saturation-state sensitivity of marine bivalve larvae to ocean acidification. Nat Clim Change 5:273-280

Watson SA, Lefevre S, McCormick MI, Domenici P, Nilsson GE, Munday PL (2013) Marine mollusc predator-escape behaviour altered by near-future carbon dioxide levels. Proc R Soc B 281:20132377

*Werner EE, Peacor SD (2003) A review of trait mediated indirect interactions in ecological communities. Ecology 84:1083-1100

* Wu F, Wang T, Cui S, Xie Z and others (2017) Effects of seawater $\mathrm{pH}$ and temperature on foraging behavior of the Japanese stone crab Charybdis japonica. Mar Pollut Bull 120:99-108

Famada SB, Boulding EG (1998) Claw morphology, prey size selection and foraging efficiency in generalist and specialist shell-breaking crabs. J Exp Mar Biol Ecol 220: 191-211

Submitted: December 12, 2018; Accepted: March 4, 2019 Proofs received from author(s): April 10, 2019 